\title{
Benedict XVI and the Limits of Scientific Learning
}

\author{
ALESSANDRO GIOSTRA \\ Deputazione di Storia Patria per le Marche, Ancona, Italy \\ giostra.al@libero.it \\ ORCID: 0000-0003-0856-8082
}

\begin{abstract}
In a scientific context such as ours, a true understanding of faith needs a correct approach to its relationship with science. Defending religious belief in the modern age dominated by scientific learning is the main preoccupation expressed by Pope Benedict XVI in some of his own speeches. Tackling this task means changing the nature of our ideas on both science and faith. The belief in God is compatible with science, only if we demarcate the limits of the scientific discourse. The idea that science is the framework for all kinds of cultural inquiry proves incorrect and represents a considerable risk for humanity. Moreover, a naturalist approach cannot respond to the exigency of finding a more profound meaning in natural reality.
\end{abstract}

Keywords: Ratzinger; science; faith; epistemology; metaphysics.

\section{Introduction}

In professional and popular culture it is not uncommon to consider atheism and science associated. On the contrary, a strict definition of scientific investigation shows the impossibility of a conflict between science and faith. This paper deals with Pope Benedict XVI's view on the relationship 
between those disciplines. More in detail, this work takes into account his own ideas on that delicate matter presented in some of his speeches delivered to a range of cultural authorities during the years of his pontificate. They are collected in a book, published in Italian (Ratzinger 2010). In this work, the notes refer to the pages of that Italian publication, while the reported texts are taken from the Vatican Website's English translation of the same speeches. (https://w2.vatican.va/content/benedict-xvi/en/speeches.index. html\#speeches) Ratzinger's words reveal both a striking sensitivity to that argument and a deep learning on the pivotal questions of a debate, which has directly involved the Church in the last decades. The consideration of science as part of a broader search for truth leads Benedict XVI to highlight the limits of the scientific approach and criticize the belief that science alone can make sense of natural reality.

\section{The limits of science}

A couple of preliminary definitions are required in order to promote a debate on the science-faith interaction. No irresolvable conflicts, indeed, can exist between science and faith unless we make confusion about their distinctive features. The modern concept of science originated in the age of the Scientific Revolution, during which a qualitative and teleological vision of the universe has been replaced by a quantitative and mechanistic worldview. Mathematical equations describing the motion of bodies can be seen as the outcome of the new way of investigating nature. As the Hungarian philosopher Stanley Jaki has declared in one of his latest works, science

has its raison d'être in a rigorous and consistent recourse to measurements, all of which imply the use of numbers, most of all the numbers called integers. Strange as it may seem, even in scientific circles this fact fails to be weighed in its true significance. As for religion, it is either defined or should be abandoned. [...] When this is done, it becomes clear that its propositions or dogmas have nothing to do with measurements or the use of numbers. Therein lies the impossibility of a conflict of that religion with exact science. (Jaki 2009, vii) 
Thus, science pertains to quantities and that conceptual peculiarity represents its limit, namely an impassable divide often ignored by intellectuals of any sort, and even by professional scientists. Supporters of naturalism, for instance, deem science to be a kind of all-encompassing learning, whose method and contents should be adopted in all other areas of knowledge.

The history of science in the twentieth century is one of undoubted achievement and major advances. Unfortunately, the popular image of twentieth-century science is sometimes characterized otherwise, in two extreme ways. On the one hand, science is posited by some as a panacea, proven by its notable achievements in the last century. Its innumerable advances were in fact so encompassing and so rapid that they seemed to confirm the point of view that science might answer all the questions of man's existence, and even of his highest aspirations. (Ratzinger 2010, 241-242)

Considering science as the only reliable way to understand nature, prevents researchers and common people from recognizing the essence of the scientific discourse, as

the scientific method itself, in its gathering of data and in the processing and use of those data in projections, has inherent limitations that necessarily restrict scientific predictability to specific contexts and approaches. Science cannot, therefore, presume to provide a complete, deterministic representation of our future and of the development of every phenomenon that it studies. (Ratzinger 2010, 218)

Supporting a deterministic approach to knowledge broadly conceived, and not only in the investigation of natural phenomena, implies the uselessness of those disciplines, such as philosophy, that are not reducible to quantification and provide science with a wider view preceding empirical research. "This increasing advance of science, and especially its capacity to master nature through technology, has at times been linked to a corresponding retreat of philosophy, of religion, and even of the Christian faith". (Ratzinger 2010, 215) 
Scientists often deny the philosophical reason's contribution to analyzing the most general characteristics of reality and serving as a wide field for further reflection and debate. "Scientific and technological breakthroughs, which fides is increasingly challenged to face, have modified the age-old concept of ratio; in a certain way they have marginalized the reason that was seeking the ultimate truth of things in order to make room for a reason content with discovering the contingent truths of the laws of nature". (Ratzinger 2010, 229)

"Positivism, in a manner of speaking, decapitates philosophy". (Husserl $1970,9)$ In this statement by Edmund Husserl, one can find the sense of Benedict XVI's criticism to a reductionist science, which neglects the relevance of a deeper meaning in natural knowledge. Naturalism is an influential creed in academic circles, and contemporary scientific research often tends to deny the key function played by metaphysics, the only one discipline able to distinguish the various branches of learning and provide natural investigation with an ontological ground. One can agree with naturalists that ideas about the divine intervention in physical and biological processes should not be introduced in scientific research. Moreover, any kind of concordism should be refuted by any genuine Christian interested in scientific matters. However, science cannot reach all aspects of reality, including the inner reasons of the existence of matter. The existence of a world in itself cannot be restricted to efficient causes and mathematical calculations. In other words, science starts with a registering of the external reality, whose analogical order is presupposed by scientists. They found their work on the commonality of phenomena belonging to a universe whose behavior does not depend on human knowledge: "The intelligibility of creation, in fact, is not the result of the scientist's effort, but a condition offered to him to enable him to discover the truth that is present within it". (Ratzinger 2010, 230)

Science presupposes the belief in a natural order and in the existence of a mind, separated from objects, whose ability lies in grasping the real essence of phenomena. This recourse to ontological and epistemological realism entails the acceptance of the inner consistency of natural harmony and its intelligibility. So that double basis, namely the presence of a harmonic nature 
and a mind as a protagonist of scientific inquiry, lies beyond the realm of science and makes the scientific activity possible. Within that perspective, the metaphor of the Book of Nature, which inspired the main protagonists of the Scientific Revolution, forms integral part of Ratzinger's thought. Galileo Galilei's words give no space to any doubt about the scientific exactness depending on the divine creation:

Philosophy is written in this grand book which is continually open before our eyes - I mean the "Universe - but before we can understand it we need to learn the language and recognize the characters in which it is written. It is written in the language of mathematics, and its characters are triangles, circles, and other geometrical figures, without which it is humanly impossible to understand a word of what it says. Without these, it is just wandering aimlessly in a baffling maze. (Galileo 2012, 115)

Also evolutionary theories, far from being incompatible with Christian doctrine, bear witness to the influence exerted by the Christian worldview on biology. Cultural popularisers still ignore that the scientific account of the species' origin is not an exhaustive explanation, as many doubts persist on the exact mechanism of evolution. As regards to Darwin, his view has never represented a threat to biblical contents, even if the naturalist propaganda hailed his works "as the ultimate weapon to vanquish the supernatural". (Jaki 1996, 145) Furthermore, reading an anthology of the texts of the most eminent representatives of the Scientific Revolution would be enough to find a confirmation of the following statement and understand how Christianity has offered an essential contribution to the emergence of exact science.

To evolve literally means to unroll a scroll, that is, to read a book. The imagery of nature as a book has its roots in Christianity and has been held dear by many scientists. Galileo saw nature as a book whose author is God in the same way that Scripture has God as its author. It is a book whose history, whose evolution, whose writing and meaning, we read according to the different approaches of the sciences, while all the time presupposing the foundational presence of the author who has wished to reveal himself therein. This image also helps us to understand that the world, far from originating out of chaos, resembles an 
ordered book; it is a cosmos. Notwithstanding elements of the irrational, chaotic and the destructive in the long processes of change in the cosmos, matter as such is legible. It has an inbuilt mathematics. (Ratzinger 2010, 234-235)

Just as Galileo trusted in a superior divine providence creating a cosmos arranged in mathematical order and providing humans with the means to understand it, Ratzinger establishes the necessity to go beyond quantifiable phenomena and find a profound rationality being part of a supreme design:

The human mind therefore can engage not only in a "cosmography" studying measurable phenomena but also in a "cosmology" discerning the visible inner logic of the cosmos. We may not at first be able to see the harmony both of the whole and of the relations of the individual parts, or their relationship to the whole. Yet, there always remains a broad range of intelligible events, and the process is rational in that it reveals an order of evident correspondences and undeniable finalities: in the inorganic world, between microstructure and macrostructure; in the organic and animal world, between structure and function; and in the spiritual world, between knowledge of the truth and the aspiration to freedom. Experimental and philosophical inquiry gradually discovers these orders; it perceives them working to maintain themselves in being, defending themselves against imbalances, and overcoming obstacles. And thanks to the natural sciences we have greatly increased our understanding of the uniqueness of humanity's place in the cosmos. (Ratzinger 2010, 235)

Therefore, the limits of the scientific method allow faith and philosophy to claim their crucial role in the hierarchy of learning, within which science is only the quantitative branch of a wider tree of knowledge rooted in realist metaphysics.

Philosophy and theology might make an important contribution to this fundamentally epistemological question by, for example, helping the empirical sciences to recognize a difference between the mathematical inability to predict certain events and the validity of the principle of causality, or between scientific indeterminism or contingency (randomness) and causality on the philosophical level. (Ratzinger 2010, 218) 
The unsuccessful attempt made by Positivist thinkers, who aimed at reducing learning as a whole to scientific contents and methods, is well known to historians. The impossible restriction of all knowledge into matter and motions described by mathematical equations is what many contemporary epistemologists have highlighted. In his address to the participants in the plenary assembly of the Pontifical Council for Culture, Benedict XVI probably refers to the response given by Pierre Simon de Laplace when Napoleon remarked the absence of God in the French astronomer's planetary mechanics. Laplace's most significant result in astronomical investigation consists in the elimination of anomalies in the planetary system conceived by Isaac Newton, who relied on divine action as an essential ground to ensure the stability of the universe. In the following notorious statement Laplace starts from mechanics and geometry, in order to extend his own deterministic worldview to other areas of human knowledge. His thought can be deemed the main source of inspiration for subsequent generation of Positivist thinkers, who tended to reduce all aspects pertaining to human beings and their existential dimension into naturalistic terms.

We ought then to regard the present state of the universe as the effect of its anterior state and as the cause of the one which is to follow. Given for one instance an intelligence which could comprehend all the forces by which nature is animated and the respective situation of the beings who compose it - an intelligence sufficiently vast to submit these data to analysis - it would embrace in the same formula the movements of the greatest bodies of the universe and those of the lightest atom; for it, nothing would be uncertain and the future, as the past, would be present to its eyes. The human mind offers in the perfection which it has been able to give to astronomy, a feeble idea to this intelligence. Its discoveries in mechanics and geometry, added to that of universal gravity, has enabled it to comprehend in the same analytical expressions the past and the future states of the system of the world. Applying the same method to other objects of its knowledge, it has succeeded in referring to general laws observed phenomena and in foreseeing those which given circumstances ought to produce. (Laplace 1902, 4) 
This scientific result and the will to eliminate any metaphysical and/or theological presupposition from astronomy, are the reasons why he is said to have replied to Napoleon that he had no need of the divine presence. Furthermore, he tried to demonstrate the origin of the Solar System as the outcome of mere physical forces. Laplace was among the beginners of that cosmological conception grounded on the idea of a self-creating universe, and his mechanistic interpretation of knowledge inspired Ratzinger's meditation.

The result was that contemporary man often had the impression that he no longer needs anyone in order to understand, explain and dominate the universe; he feels the centre of everything, the measure of everything [...] the formula "Etsi Deus non daretur" is increasingly becoming a way of living that originates in a sort of "arrogance" of reason [...] that deems itself self-sufficient and closes itself to contemplation and the quest for a superior Truth. (Ratzinger 2010, 223)

The search for an ultimate truth fully involves our spiritual dimension, aiming at watching nature as an ordered whole established by the Creating Logos. Achieving the goal of universal truth should accompany the work of scientists and the beliefs of common people.

Scientific activity ultimately benefits from the recognition of man's spiritual dimension and his quest for ultimate answers that allow for the acknowledgement of a world existing independently from us, which we do not fully understand and which we can only comprehend in so far as we grasp its inherent logic. Scientists do not create the world; they learn about it and attempt to imitate it, following the laws and intelligibility that nature manifests to us. The scientist's experience as a human being is therefore that of perceiving a constant, a law, a Logos that he has not created but that he has instead observed: in fact, it leads us to admit the existence of an all-powerful Reason, which is other than that of man, and which sustains the world. This is the meeting point between the natural sciences and religion. (Ratzinger 2010, 243)

The intelligibility of nature as a whole is offered to scientists by metaphysics as a broader view. It includes in its domain the search for an ultimate truth 
as an unavoidable tendency of human mind, whose goal goes much beyond empirical investigation.

One of the typical misunderstandings in the science-faith relationship lies in the belief, held by some scientists, to eradicate the basic principles of faith, creation out of nothing being the most discussed issue. Christian revelation announces creation out of nothing as the first step of the divine design, and just the criticism to that dogma displays the error committed by naturalists, who are not aware of their own betraying the correct scientific method. Quantitative investigation of nature will never be able to determine the 'nothing' or perform an experiment to demonstrate its reality, as the 'nothing' is not a scientific term. Science begins from observable reality to formulate equations related to physical states and to develop theories about what is still unknown. So the impossibility to say something on the 'nothing' just represents an impassable divide for scientific disciplines. All in all, only remaining within their respective dominions, science and faith can engage in a fruitful dialogue.

There is no opposition between faith's understanding of creation and the evidence of the empirical sciences [...] A decisive advance in understanding the origin of the cosmos was the consideration of being qua being and the concern of metaphysics with the most basic question of the first or transcendent origin of participated being. In order to develop and evolve, the world must first be, and thus have come from nothing into being. It must be created, in other words, by the first Being who is such by essence. (Ratzinger 2010, 233-234)

\section{Science and ethics}

Also the ethical dimension of natural knowledge can be founded on the distinction of the respective realms of science and faith. To put it more simply, recalling that science deals with everything gravitating around the quantification of phenomena is the only way to evaluate the importance of ethics in scientific research. Only admitting that a broader search for truth is a vital characteristic of science, we can understand that the scientific enterprise cannot be deemed to be value-free. 
Knowledge, in a word, must be understood and pursued in all its liberating breadth. It can certainly be reduced to calculation and experiment, yet if it aspires to be wisdom, capable of directing man in the light of his first beginnings and his final ends, it must be committed to the pursuit of that ultimate truth which, while ever beyond our complete grasp, is nonetheless the key to our authentic happiness and freedom (cf. Jn 8:32), the measure of our true humanity, and the criterion for a just relationship with the physical world and with our brothers and sisters in the great human family. (Ratzinger 2010, 239)

Naturalistic ethics aims at deriving ethical values from the knowledge of natural reality. That is the case of Positivism, whose account of science minimizes its relationship with moral issues. Considering ethics in naturalistic terms implies the absence of any supernatural principle and a substantive commitment to scientific investigation. Ignoring the existence of bioethical principles in biological research is a clear instance of a science excluding humanity from its main goals, as human life can be encountered only in real humans. Unfortunately bioethics, as commonly understood by a large part of scientific community, is proceeding without real ethical foundations. As a result, in a historical age, such as the contemporary, during which the need for a suitable bioethics should be obvious, that discipline is becoming a sort of ethics engaged more in manipulating life than preserving life itself. "The lure of the technically sweet is a variant of countless other sweet lures that have so far played havoc with mankind, beginning with that presumably sweet fruit of a very specific tree in the Garden of Eden” (Jaki 2000, 183). Moreover, the toleration of unethical behaviors in technological applications often reflects the inability of scientists to oppose economic and political interests. The proliferation of atomic weapons just stands for the moral impotence of contemporary society.

Science, however, while giving generously, gives only what it is meant to give. Man cannot place in science and technology so radical and unconditional a trust as to believe that scientific and technological progress can explain everything and completely fulfil all his existential and spiritual needs. Science cannot replace philosophy and revelation by giving an exhaustive answer to man's most radical 
questions: questions about the meaning of living and dying, about ultimate values, and about the nature of progress itself. (Ratzinger 2010, 216-217)

Making confusion about what is ethically acceptable and what is scientifically true, or simply works, entails a serious risk for humanity. The manipulation of phenomena and scientific laws without paying attention to negative consequences represents the obvious result of that erroneous approach to ethics.

For this reason, the Second Vatican Council, after acknowledging the benefits gained by scientific advances, pointed out that the "scientific methods of investigation can be unjustifiably taken as the supreme norm for arriving at truth", and added that "there is a danger that man, trusting too much in the discoveries of today, may think that he is sufficient unto himself and no longer seek the higher values. (Ratzinger 2010, 217)

Thus, confusing science with ethics is, first and foremost, an epistemological mistake due to a naturalistic mentality, according to which even moral aspects are subdued to scientific contents and method. Of course, the negative consequences of that erroneous worldview are not restricted into the dominion of exact knowledge."Nonetheless, it happens that scientists do not always direct their research to these aims. Easy earnings or, even worse, the arrogance of replacing the Creator, at times play a decisive role. This is a form of the hybris of reason, which can acquire characteristics that are dangerous to humanity itself". (Ratzinger 2010, 229)

The objectivity of science can be very helpful for a reaction against ethical relativism, because scientific contents can prove enormously useful to understand our place in nature. Only evaluating science to be part of a wider search for truth it is possible to focus on responsibility as a major area in which to re-establish the science-ethics relations.

Science, moreover, is unable to work out ethical principles; it can only accept them and recognize them as necessary to eradicate its potential pathologies. In this context, philosophy and theology become indispensable aids which must be placed alongside science in order to prevent it from proceeding on its own down 
a twisting path, full of unexpected accidents and not without risks. This does not mean restricting scientific research or preventing technology from producing the means for development; rather, it consists in maintaining vigilance about the sense of responsibility that reason possesses in regards to science, so that it stays on track in its service to the human being. (Ratzinger 2010, 229-230)

Ethics in scientific research depends on the purpose of science as a truth-searching activity. Despite the fact that some essentials of Christian ethics are fully rational and understandable also by unbelievers, a careful consideration of the history of thought highlights Christian doctrine as a proper background to fulfil that objective. A clear cut distinction between what is ethically good or evil requires the acceptance of some basic affirmations about life. "Those propositions were first held and are still held as a set only within a genuinely Christian context”. (Jaki 2007, 50). The idea of the world as the result of the Creating Word led the Western milieu to the achievement of exact science, and the same revealed Word is the main instrument to avoid unethical behaviors in research.

Passion for the truth impels us to re-enter into our interior selves to grasp the profound meaning of our lives. True philosophy must take every person by the hand and bring them to discover how fundamental it is to their dignity to know the truth of Revelation. Before this demand for meaning, which gives no respite until it flows into Jesus Christ, the Word of God reveals his character as a definitive response: one Word of revelation that becomes life and that asks to be welcomed as an inexhaustible source of truth. (Ratzinger 2010, 231)

Christian faith is a valid response to the ethical challenge posed by the advancement of scientific learning. If human beings are mere matter, we cannot appeal to the notion of human dignity or the establishment of inalienable rights belonging to individuals. "Science measures, which is its essential method (a word that means road charting or simply moving along a given road), but the scientific method is a blind alley when it comes to life. There are no units for measuring life, even mere biological life”. (Jaki 2007, 116)

The failure of naturalistic ethics is symptomatic of the deeper failure of the materialist attempt to build a livable society on science as an all-estab- 
lishing authority. In materialistic terms, the passive acceptance of science as an absolute truth, independent from moral principles, leans weight to doctrines such as Social Darwinism. It emphasizes profit and competition as unavoidable characteristics of a social ongoing process excluding weaker members. Naturalists can be atheist or consider God as a supreme cosmic engineer, who has designed an aimless world. On the contrary, as humans, our behavior is grounded upon that eternal life of God providing his own intelligent creatures with the possibility to exercise freedom and fulfill their task. In sum, ethical issues depend on science as a truth-seeking enterprise and only the belief in the Creating Logos integrates scientific knowledge and human progress in a very effective synthesis.

Scientific achievement in this new century should always be informed by the imperatives of fraternity and peace, helping to solve the great problems of humanity, and directing everyone's efforts towards the true good of man and the integral development of the peoples of the world. The positive outcome of twenty-first century science will surely depend in large measure on the scientist's ability to search for truth and apply discoveries in a way that goes hand in hand with the search for what is just and good. With these sentiments, I invite you to direct your gaze toward Christ, the uncreated Wisdom, and to recognize in His face, the Logos of the Creator of all things. (Ratzinger 2010, 243-244)

\section{Conclusion}

Science is not sufficient to explain the world as a whole, because the universe available to scientific research is restricted to calculations and experimental method. "Science simply takes the existence of the world for granted" (Gilson 1959,68 ), and although scientists are not obliged to believe in God, the limits of the scientific discourse makes the presence of a Creator entirely rational. As Benedict XVI rightly points out, scientific activity and common sense presuppose the existence of a universe (unum in diversis), that is an ordered whole of interacting phenomena. The failure to establish a limitless science makes the exclusive domain of faith an indispensable source for a correct approach to knowledge. That is only one of the unmistakable evidences for 
the reliability of a religion as "a conscious appreciation of and response to the mystery that grounds, embraces and transcends both nature and ourselves". (Haught 2006, 22) Limit means restriction, a very unpopular word among those scientists who do not understand that going beyond quantities and denying the dependence of their discipline on a broader view imply the end of scientific enterprise.

\section{References}

Galilei, Galileo. 2012. Selected Writings. Translated by William Shea and Mark Davies. Oxford: Oxford University Press.

Gilson, Etienne. 1959. Elements of Christian Philosophy. Garden City: Doubleday. Haught, John. 2006. Is Nature Enough? Meaning and Truth in the Age of Science, Cambridge: Cambridge University Press.

Husserl, Edmund. 1970. The Crisis of European Sciences and Transcendental Phenomenology. Evanston: Northwestern University Press.

Jaki, Stanley. 1996. Bible and Science. Front Royal: Christendom Press.

Jaki, Stanley. 2000. The Savior of Science. Grand Rapids: Eerdmans Publishing Company.

Jaki Stanley. 2007. The Ethical Foundations of Bioethics. Port Huron: Real View Books. Jaki, Stanley. 2009. The Mirage of Conflict between Science and Religion. New Hope: Real View Books.

Laplace, Pierre Simon. 1902. A Philosophical Essay on Probabilities. Translated by Frederick Wilson Truscott. New York: Robert Drummond Printer.

Ratzinger, Joseph. 2010. Fede e Scienza: Un Dialogo Necessario. Torino: Lindau.

Ratzinger, Joseph. Speeches. https://w2.vatican.va/content/benedict-xvi/en/speeches. index.html\#speeches

Szetela, Monika, and Grzegorz Osiński. 2017. "The Concept of 'Dialogical Soul' by Joseph Ratzinger against the latest concepts of neuroscience." Scientia et Fides 5, 2: 199-215. 